ARTICLE

\title{
A membrane-free flow electrolyzer operating at high current density using earth-abundant catalysts for water splitting
}

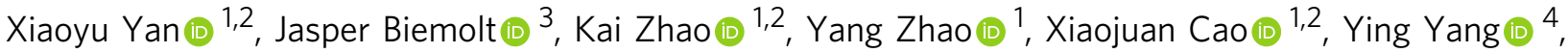 \\ Xiaoyu Wu (1) ${ }^{1,2}$, Gadi Rothenberg (D) $^{3}$ \& Ning Yan (1,2,3凶
}

Electrochemical water splitting is one of the most sustainable approaches for generating hydrogen. Because of the inherent constraints associated with the architecture and materials, the conventional alkaline water electrolyzer and the emerging proton exchange membrane electrolyzer are suffering from low efficiency and high materials/operation costs, respectively. Herein, we design a membrane-free flow electrolyzer, featuring a sandwich-like architecture and a cyclic operation mode, for decoupled overall water splitting. Comprised of two physically-separated compartments with flowing $\mathrm{H}_{2}$-rich catholyte and $\mathrm{O}_{2}$-rich anolyte, the cell delivers $\mathrm{H}_{2}$ with a purity $>99.1 \%$. Its low internal ohmic resistance, highly active yet affordable bifunctional catalysts and efficient mass transport enable the water splitting at current density of $750 \mathrm{~mA} \mathrm{~cm}^{-2}$ biased at $2.1 \mathrm{~V}$. The eletrolyzer works equally well both in deionized water and in regular tap water. This work demonstrates the opportunity of combining the advantages of different electrolyzer concepts for water splitting via cell architecture and materials design, opening pathways for sustainable hydrogen generation.

\footnotetext{
${ }^{1}$ School of Physics and Technology, Wuhan University, Wuhan, China. ${ }^{2}$ Suzhou Institute of Wuhan University, Suzhou, China. ${ }^{3}$ Van't Hoff Institute for Molecular Sciences (HIMS), University of Amsterdam, Amsterdam, The Netherlands. ${ }^{4}$ Hubei Key Laboratory of Theory and Application of Advanced Materials Mechanics, Wuhan University of Technology, Wuhan, China. ${ }^{凶}$ email: ning.yan@whu.edu.cn
} 
R eplacing the fossil fuels in today's energy portfolio is a grand challenge of the sustainable society ${ }^{1-3}$. Among all the proposed alternatives, hydrogen generated electrochemically using water and renewable energy sources has been regarded as one of the best, if not the ultimate, solutions ${ }^{4-7}$. The conventional alkaline water electrolyzer dates back in $1789^{8,9}$. It enables the use of cost-effective catalysts for both the hydrogen evolution reaction (HER) and oxygen evolution reaction (OER), enjoying low capital expenditure and operating expenses ${ }^{10}$. Yet, as the anode and cathode are separated by a porous diaphragm, the potential mixture of $\mathrm{H}_{2}$ and $\mathrm{O}_{2}$ brings safety concerns. The resulting high ohmic resistance often precludes the operation at high current density ${ }^{1-13}$. Recently, the polymer membrane electrolyzer has been highlighted as the next-generation candidate ${ }^{14}$. Particularly, the proton-exchange membrane (PEM) based one dominates, allowing operation at high current density $\left(>1 \mathrm{~A} \mathrm{~cm}^{-2}\right)$ while delivering pressurized high-purity $\mathrm{H}_{2}(>99 \%)^{15,16}$. Nonetheless, only noble metal catalysts can survive in the corrosive environment of the cell ${ }^{17}$. Besides, deionized water must be used to reduce membrane degradation ${ }^{18,19}$. The high cost is thus a prominent barrier impeding large-scale application ${ }^{20,21}$. Anion-exchange membrane (AEM) electrolyzers seem preferable in this context, as affordable materials can be used. The problem is that the durability of state-of-the-art AEMs is often only $\sim 1000 \mathrm{~h}^{22}$.

Since the performance of conventional water electrolyzers is inherently constrained by their architecture and configuration, various cell designs have emerged to tackle these limitations. One promising alternative is to circumvent the need for a membrane by decoupling the OER and HER spatially and/or temporarily in overall water splitting 17,23-26. Compared with the electrolyzers containing solid membranes, this membrane-free cell is less complex, potentially more robust in the harsh reaction environments, and cheaper. Moreover, it can operate using different aqueous electrolyte ${ }^{27}$. For example, Cronin and co-workers used phosphomolybdic acid as the "electron buffer" to spatially decouple the OER and HER. Other (in)soluble redox mediators were also proposed, such as $\left[\mathrm{Fe}(\mathrm{CN})_{6}\right]^{4-} /\left[\mathrm{Fe}(\mathrm{CN})_{6}\right]^{3-}, \mathrm{V}^{3+} / \mathrm{V}^{4+}$ and $\mathrm{NiOOH} / \mathrm{Ni}(\mathrm{OH})_{2}{ }^{28-32}$. A further advantage of this approach is that it offers the opportunity of coupling water splitting with battery technologies for concurrent energy storage ${ }^{33,34}$. Membrane-free electrolysis is scalable. For instance, the divergent electrode-flow-through (DEFT) membraneless alkaline electrolysis takes advantage of the divergent flow of electrolyte to maintain gas separation while delivering excellent performance in a pilot plant ${ }^{35,36}$.

Notwithstanding these advantages, many membrane-free cells suffer from large ohmic drops. In fact, while the ionic conductivity of concentrated $\mathrm{KOH}$ and $\mathrm{H}_{2} \mathrm{SO}_{4}$ solution is higher than that of the membrane, yet the travel distance of ions is typically at the millimeters scale, which is much longer than the thickness of membrane electrolyte $(\approx 100-200 \mu \mathrm{m})^{37}$. This is one of the key factors leading to the much lower working current densities and higher working voltages $(>2.5 \mathrm{~V})^{38}$. Herein, we design a membrane-free flow electrolyzer featuring a sandwich-like architecture for decoupled water splitting. Though comprising of two symmetric compartments, it features the low internal ohmic resistance and efficient mass transport, allowing the operation at high current density with low overpotential. Importantly, the bifunctional catalysts are based on affordable Fe/Co compounds, which opens opportunities for real-life applications.

\section{Results}

Membrane-free flow electrolyzer configuration. Figure 1a shows the assembly and working principle of the membrane-free flow electrolyzer (MFE). The cell comprises two physically separated compartments, connected by wires that allows the transfer of electrons, for oxygen evolution and hydrogen evolution reactions, respectively. Both compartments share the same sandwich-like configuration, comprising of endplates, current collectors, a bifunctionally active electrode, a $130 \mu \mathrm{m}$-thick porous separator, and an auxiliary electrode $\left(\mathrm{AE}, \mathrm{NiOOH} / \mathrm{Ni}(\mathrm{OH})_{2}\right.$ redox couple). The anolyte $\left(\mathrm{O}_{2}\right.$-rich $1.0 \mathrm{M} \mathrm{KOH}$ solution $)$ and catholyte $\left(\mathrm{H}_{2}\right.$-rich $1.0 \mathrm{M} \mathrm{KOH}$ solution) are directed to flow to the designated compartment continuously during the reaction. Thanks to this closely packed sandwich structure with a much shorter travel distance of the ions, the ohmic resistance of our membrane-free cell is comparable with that of the proton exchange membrane water electrolyzer (PEMEC, vide infra). Together with the separation of two reaction chamber, this opens opportunities for the cell to work at high current densities that are comparable with PEMEC.

Our cell works cyclically during water splitting. In the cycle when the left compartment is the cathode (see Fig. 1b), the bifunctional catalyst on the working electrode catalyzes the HER in the catholyte, generating $\mathrm{OH}^{-}$anions which pass through the separator and react with $\mathrm{Ni}(\mathrm{OH})_{2}$ at the $\mathrm{AE}$ to form $\mathrm{NiOOH}$. The evolved $\mathrm{H}_{2}$ gas is collected in the $\mathrm{H}_{2}$ tank via a 3-way valve. In the meantime, the working electrode in the other compartment catalyzes the OER in the anolyte, using the $\mathrm{OH}^{-}$ions supplied by the conversion of $\mathrm{NiOOH}$ into $\mathrm{Ni}(\mathrm{OH})_{2}$. The formed $\mathrm{O}_{2}$ also flows through another 3-way valve to the $\mathrm{O}_{2}$ tank (or to the vent upon request). When the AE materials are nearly all converted, the continuous operation of the system is guaranteed by switching the electrical current polarity of the cell as shown in Fig. 1c and Supplementary Fig. 8. As the left compartment becomes the anode in the following cycle, the catholyte is replaced by the $\mathrm{O}_{2}$-rich anolyte beforehand. This swap was designed to avoid the mixture of the residual $\mathrm{H}_{2}$ and $\mathrm{O}_{2}$ left in the compartment. The 3-way valve is also switched to the direction to ensure the formed $\mathrm{O}_{2}$ flows to $\mathrm{O}_{2}$ tank. Meanwhile, the rightside compartment and the accessories behave accordingly to ensure the generation and collection of $\mathrm{H}_{2}$ with high purity. Because the electrode catalyst is OER/HER bifunctionally active, this cyclical operation shows essentially identical and excellent performance in all cycles.

Bifunctional electrocatalyst. To ensure the excellent bifunctional activity, efficient mass transport, high electrical conductivity, and good physical compatibility with the electrode, we designed the hierarchically porous catalyst comprising $\mathrm{FeP}$, CoP and nitrogen doped carbon (NC). This hybrid system, denoted as FeP-CoP/ $\mathrm{NC}$, was synthesized through the sequential processes by confining Fe-Co precursor in the mesopores of $\mathrm{NC}$ by infiltration, forming $\mathrm{Fe}-\mathrm{Co}$ bimetallic alloy by pyrolysis, and phosphidation giving the interconnected $\mathrm{FeP}$ and CoP quantum dots (see the schematic in Fig. 2a). Figure $2 \mathrm{~b}$ shows the X-ray diffraction (XRD) pattern of the pyrolyzed NC embedded with the Co-Fe precursor. The reducing atmosphere facilitated the formation of $\mathrm{Fe}-\mathrm{Co}$ bimetallic alloy. After phosphidation, the coexistence of FeP (PDF No. 78-1443) and CoP (PDF No. 29-0497) was confirmed $^{39-45}$. The crystallized grain size of both FeP and CoP, calculated using the Scherrer equation, was $\sim 3.4 \mathrm{~nm}$. In fact, as $\mathrm{FeP}$ and $\mathrm{CoP}$ are immiscible, doping $\mathrm{FeP}$ with $\mathrm{Co}$ or vice versa to optimize the catalytic performance is challenging 46,47 . The alloying step created the homogenously dispersed $\mathrm{Fe}$ and $\mathrm{Co}$ phase at the atomic level, contributing to the generation of the small nanocrystals of $\mathrm{CoP}$ and FeP. Such small domains maximized the length of the FeP-CoP interface for improved bifunctional catalysis (vide infra) ${ }^{48}$. 

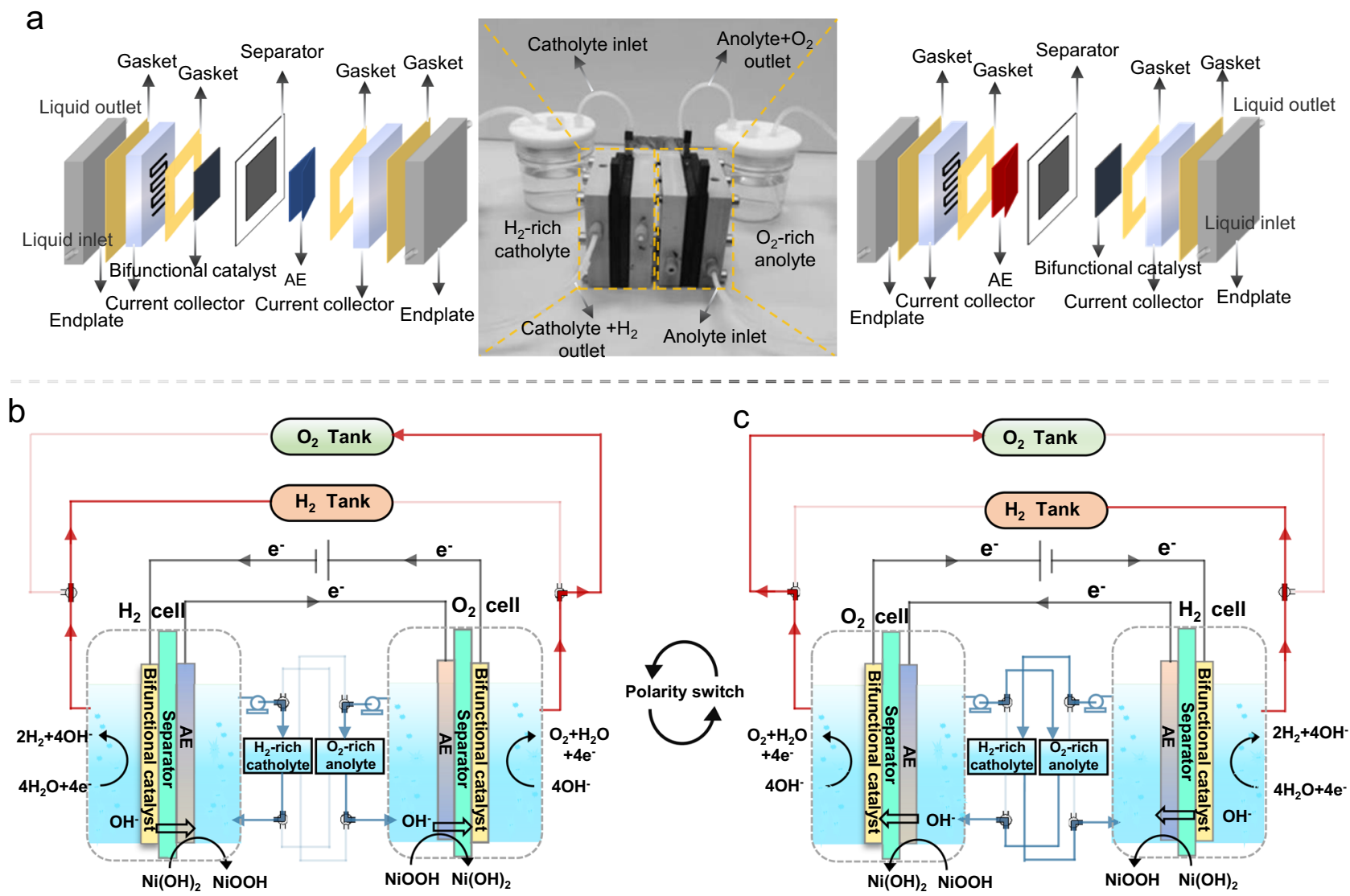

Fig. 1 The configuration and working principle of the membrane-free flow electrolyzer. a The components and assembly of the membrane-free flow electrolyzer. b, c The detailed cyclical working principle of the membrane-free flow electrolyzer, showing how the roles of each compartment are reversed during the operation.

The morphology of the pristine NC was characterized using transmission electron microscope (TEM, Fig. 2c). This hierarchically porous structure contains abundant micro-, meso-, and macropores (the latter two are demonstrated by the circles, also see the $\mathrm{N}_{2}$ adsorption isotherm and the corresponding pore size distribution analysis in Supplementary Fig. 10). After embedding $\mathrm{FeP}$ and $\mathrm{CoP}$, the TEM image in Fig. $2 \mathrm{~d}$ shows that the phosphide cluster are mainly confined in the large pores of $\mathrm{NC}$, yet not fully occupied the mesopore space. The comparison of the pore size distribution curve also indicates the pores, sizing between 20 and $50 \mathrm{~nm}$, were retained after filling in the phosphide catalyst. The carbon backbones minimized the ohmic loss, whereas the remaining pores is vital for the mass transport. Thus, this hybrid catalyst is critical for operating the electrolyzer at high current density.

The formation of $\mathrm{FeP}$ and $\mathrm{CoP}$ cluster was also verified by energy-dispersive X-ray spectroscopy (EDX) using high-angle annular dark field detector in the scanning transmission electron microscope mode (HAADF-STEM). The clusters were $<50 \mathrm{~nm}$ in diameter in Fig. 2e. Albeit that $\mathrm{CoP}$ and FeP are immiscible, the elemental mappings show that both $\mathrm{Fe}$ and Co are uniformly distributed within the cluster (see Fig. 2f). The EDX line scan confirmed the domain size of both phosphides was $2-3 \mathrm{~nm}$, in agreement with the XRD analysis. This conclusion was also supported by the selected area electron diffraction (SAED, see the inset of Fig. 2d). The small diffuse halo rings, stemming from the (011) and (101) plane of FeP and CoP, respectively, showed that both the $\mathrm{CoP}$ and $\mathrm{FeP}$ domains were nanocrystalline.

We first used the standard three-electrode setup in $1.0 \mathrm{M} \mathrm{KOH}$ to evaluate the OER activities of the prepared electrocatalysts on the glassy carbon working electrode. Figure 3a compares the linear sweep voltammograms (LSVs) of $\mathrm{FeP}-\mathrm{CoP} / \mathrm{NC}$ with the controls. Gaining the current densities of up to 10,50 , $100 \mathrm{~mA} \mathrm{~cm}^{-2}, \mathrm{FeP}-\mathrm{CoP} / \mathrm{NC}$, with 1:1 molar ratio of $\mathrm{Fe}$ and $\mathrm{Co}$, required the lowest overpotentials $(\eta)$ of 281,340 , and $392 \mathrm{mV}$, respectively. In contrast, samples of hybrid phosphide on commercial carbon (FeP-CoP/C), FeP-CoP, and NC all showed much higher overpotentials and larger Tafel slopes (see Fig. 3c). In fact, the commercial carbon lacked the mesopores which suffered higher concentration overpotential at high current density. Unsupported $\mathrm{FeP}-\mathrm{CoP}$ was much less conductive, thus experiencing significant ohmic loss. This was proven by the Nyquist plot from the electrochemical impedance spectroscopy (EIS, see Supplementary Fig. 11). Particularly, the molar ratio of $\mathrm{Fe} / \mathrm{Co}(1: 0,1: 0.5,1: 1,0.5: 1$, and 0:1) was a critical factor affecting the OER activity (see Supplementary Fig. 12). This might be linked to the electronic structure and the synergistic effect of the catalyst (vide infra). We also studied the stability of FeP-CoP/NC via performing 1000 cyclic voltammetry (CV) cycles (see Fig. 3d). Negligible change of LSVs was observed after the cycles. Besides, we also biased the cell at the overpotential of $281 \mathrm{mV}$, steady OER current was recorded over the $12 \mathrm{~h}$ test (see the inset of Fig. 3d). The excellent bifunctionality of $\mathrm{FeP}-\mathrm{CoP} / \mathrm{NC}$ was then exhibited in the HER. At the benchmark $10 \mathrm{~mA} \mathrm{~cm}^{-2}$ current density, $\mathrm{FeP}-\mathrm{CoP} / \mathrm{NC}$ delivered an overpotential of $79 \mathrm{mV}$, comparable with the state-of-the-art catalysts (see Supplementary Tables 1 and 2). The Tafel slope was $71 \mathrm{mV} \mathrm{dec}-1$, less steep than that of $\mathrm{FeP}-\mathrm{CoP} / \mathrm{C}\left(93 \mathrm{mV} \mathrm{dec}^{-1}\right)$, FeP-CoP $\left(105 \mathrm{mV} \mathrm{dec}^{-1}\right)$, indicating more rapid reaction kinetics. Meanwhile, no activity decay was recorded after the stability test in Fig. $3 \mathrm{~h}$. 

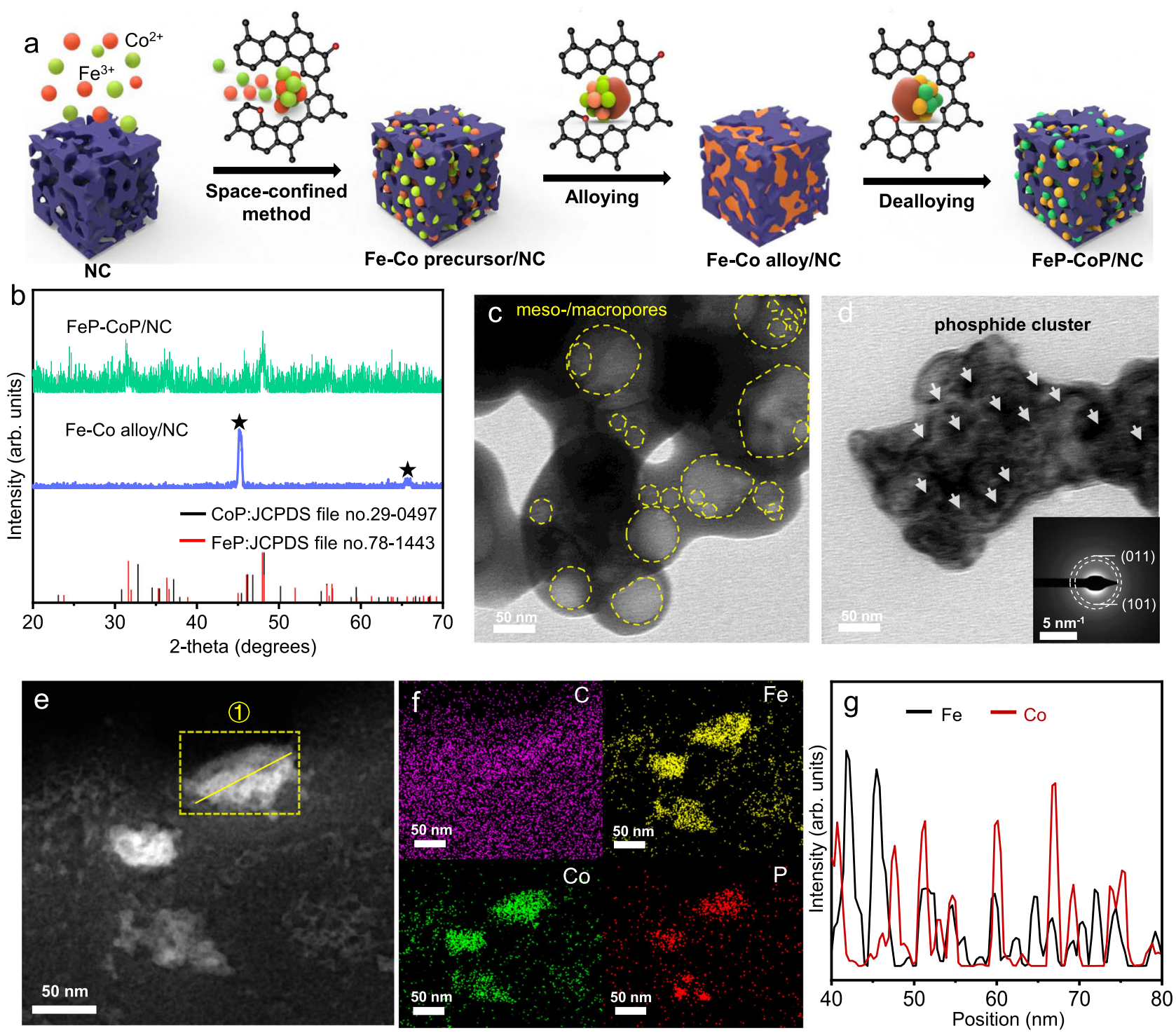

Fig. 2 The schematic synthetic procedure and characterizations of FeP-CoP/NC bifunctional catalyst. a Representative illustration of the synthetic procedure of FeP-CoP/NC; $\mathbf{b}$ XRD patterns of Fe-Co alloy/NC and FeP-CoP/NC; TEM micrographs of $\mathbf{c}$ pristine NC with meso/macropores and $\mathbf{d}$ FeP$\mathrm{CoP} / \mathrm{NC}$, the inset is the SAED pattern of FeP-CoP domains; e HAADF image of FeP-CoP/NC, EDX line scan position is indicated; $\mathbf{f}$ EDX elemental mappings of $\mathrm{C}, \mathrm{Fe}, \mathrm{Co}$, and $\mathrm{P} ; \mathbf{g}$ EDX line scan of the nanoparticle in $\mathbf{e}$.

We then explored the bifunctionality, stability, and system compatibility of FeP-CoP/NC under practical conditions. No iR compensation was applied in all the water electrolysis studies below. The hybrid catalyst was printed onto the carbon cloth as both the anode and cathode of a single compartment electrolyzer for alkaline water splitting in $1.0 \mathrm{M} \mathrm{KOH}$. At $1.68 \mathrm{~V}(\eta=$ $450 \mathrm{mV}$ ) in the overall water splitting reaction, the current density reached $55 \mathrm{~mA} \mathrm{~cm}^{-2}$, which was maintained for $36 \mathrm{~h}$ of electrolysis (Fig. 3i). In the same cell, we also exampled the stability and the dynamic response of the electrode chronopotentiometrically. Figure $3 \mathrm{j}$ shows the applied voltage responses of the cell when the current density was stepped up from 10 to $285 \mathrm{~mA} \mathrm{~cm}^{-2}\left(\Delta j=25 \mathrm{~mA} \mathrm{~cm}^{-2}\right)$. The highest potential reached $2.51 \mathrm{~V}$, due to the large ohmic resistance of the cell. Nevertheless, the potential was stabilized rapidly after each current ramp. The cyclic stability of the catalyst during cycled OER and HER was carried out by switching the potential polarity periodically $( \pm 1.68 \mathrm{~V}, 3.3 \mathrm{~h}$ per cycle, see Fig. $3 \mathrm{k}$ and Supplementary Fig. 14a). Hence, $\mathrm{FeP}-\mathrm{CoP} / \mathrm{NC}$ catalyst on each electrode was subjected to both anodic and cathodic bias. Notably, the current density of the cell stabilized at ca. $\pm 43 \mathrm{~mA} \mathrm{~cm}^{-2}$ in both the "positive" and "negative" cycle. To avoid the influence of the evolved gas around the electrode on the next cycle, we also assembled an H-type cell comprising $\mathrm{FeP}-\mathrm{CoP} / \mathrm{NC}$ on carbon cloth as both electrodes. Similar cyclic chronoamperometric studies were performed $( \pm 1.68 \mathrm{~V}, 3.3 \mathrm{~h}$ per cycle, see Fig. $3 \mathrm{l}$ and Supplementary Fig. $14 \mathrm{~b})$. Although the current density remained stable during all cycles, the value dropped to $\pm 10 \mathrm{~mA} \mathrm{~cm}^{-2}$ due to the improved ohmic resistance of the cell. We concluded that FeP-CoP/NC on carbon cloth were excellent bifunctional electrode, yet the high ohmic loss of the conventional alkaline water electrolysis cell restricted its performance in practice.

To understand the origin of the bifunctional activity, we performed X-ray photoelectron spectroscopy (XPS). The deconvoluted Fe $2 p$ core-level spectra of $\mathrm{FeP}-\mathrm{CoP} / \mathrm{NC}$ before and after HER/OER cycle is shown in Supplementary Fig. 15a. The peaks at 707.2 and $720.1 \mathrm{eV}$ of the fresh sample correspond to the formation of phosphide ${ }^{49,50}$. They disappeared completely after the reaction, plausibly due to the oxidation and the subsequent formation of iron oxide and hydroxide. CoP also experienced 

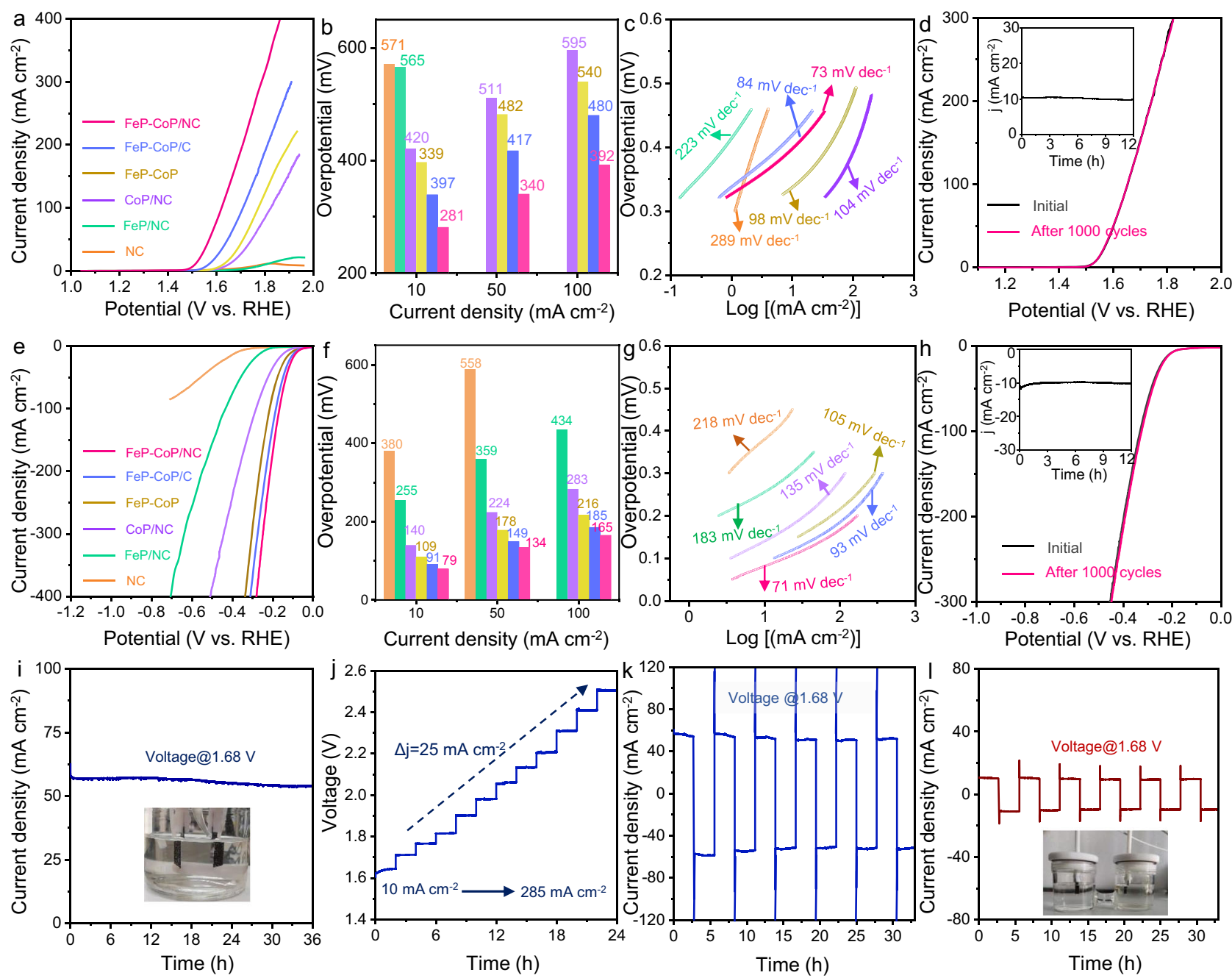

Fig. 3 The electrocatalytic performance of FeP-CoP/NC. The comparisons of a LSVs, $\mathbf{b}$ overpotentials at various current densities, $\mathbf{c}$ Tafel slopes, and $\mathbf{d}$ stability with the controls in OER. The comparisons of $\mathbf{e}$ LSVs, $\mathbf{f}$ overpotentials at various current densities, $\mathbf{g}$ Tafel slopes, and $\mathbf{h}$ stability with the controls in HER. The electrolyte is $1.0 \mathrm{M} \mathrm{KOH}$, the scan rate is $5 \mathrm{mV} \mathrm{s}^{-1}$, post-iR compensation is applied. The performance of overall water splitting using FeP-CoP/ $N C$ as the catalysts: $\mathbf{i}$ the $j$ - $t$ curve at $1.68 \mathrm{~V} ; \mathbf{j}$ the $V$ - $t$ curve at various current densities and $\mathbf{k}$ the $j$ - $t$ curve at $\pm 1.68 \mathrm{~V}$ with the potential polarity swapped every $3.3 \mathrm{~h}$ in a single compartment cell; I the $j$ - $t$ curve at $\pm 1.68 \mathrm{~V}$ with the potential polarity swapped every $3.3 \mathrm{~h}$ in a $\mathrm{H}$-cell. No $i \mathrm{R}$ compensation was applied.

oxidation and the formation of oxyhydroxide during the OER cycle, in agreement with scenario observed in the literature, yet the phosphide peaks at 779.4 and $794.5 \mathrm{eV}$ were still observed in Supplementary Fig. $15 b^{51-56}$. This might be ascribed to the electronegativity difference of $\mathrm{CoP}$ and $\mathrm{FeP}$. When connected with each other in the electrolyte, the more electropositive $\mathrm{CoP}$ was largely protected and stabilized whereas $\mathrm{FeP}$ was oxidized. Because both $\mathrm{CoP}$ and $\mathrm{FeP}$ were uniformly distributed in the nanoparticle (cf. the TEM microscopic analysis), the remaining CoP quantum dots were still capable of effectively catalyzing HER after OER cycle. Therefore, we inferred the origin of the bifunctionality: the in-situ generated mixed $\mathrm{Fe}$ and $\mathrm{Co}$ (oxy) hydroxides contributed to OER whereas the residual CoP quantum dots were responsible for HER during the continuous cyclic operation.

Performance of MFE. The FeP-CoP/NC bifunctional catalyst was screen printed on the carbon cloth (CC) as the working electrode of the MFE. Before testing, both compartments of the MFE was filled up with $1.0 \mathrm{M} \mathrm{KOH}$ solution. Selecting this relatively low concentration (compared with $30-40 \% \mathrm{KOH}$ solution in industrial alkaline water electrolyzer) was to ensure the stability of phosphide electrocatalyst in the OER cycle against oxidation. The auxiliary electrodes were activated in-situ to form the $\mathrm{Ni}(\mathrm{OH})_{2} / \mathrm{NiOOH}$ redox couple (see Fig. 1, more details can be found in the SI). Figure $4 \mathrm{~b}$ shows the cyclic galvanostatic curves of MFE at $\pm 750 \mathrm{~mA} \mathrm{~cm}^{-2}$. Each cycle lasted for $10 \mathrm{~min}$ to avoid the over discharging of the auxiliary electrode (the influence of cycle time can be found in Supplementary Fig. 16). The recorded potential bias, stabilized at $2.1 \mathrm{~V}$, was highly symmetric for all the "positive" and "negative" cycles. When the current polarity was swapped, the flowing anolyte and catholyte were also exchanged during the $2 \mathrm{~min}$ interval (for simplicity, this interval was omitted in the plots below). The $\mathrm{H}_{2}$ purity, determined at all the sampling time (see red dots in Fig. 4a), maintained $>99.1 \%$ in all the investigated cycles.

MFE can work at different current densities (see Fig. 4b). The applied voltages were $1.62,1.78,1.92,2.01$, and $2.11 \mathrm{~V}$ to reach the current densities of $150,300,450,600$, and $750 \mathrm{~mA} \mathrm{~cm}^{-2}$, respectively. The low overpotentials indicated the excellent bifunctional activity of the catalyst, comparable with the PEMEC 


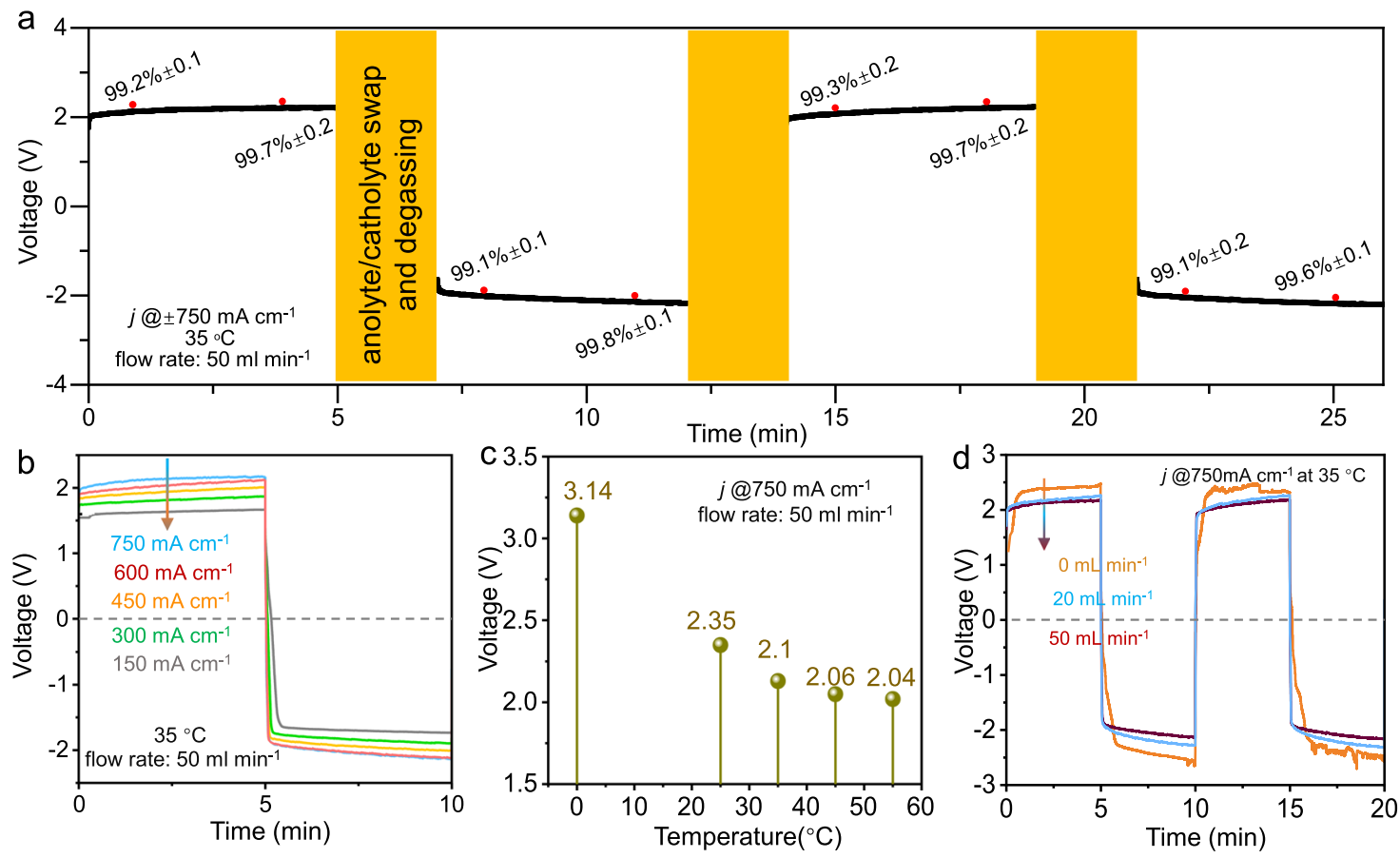

Fig. 4 The performance of MFE in overall water splitting. a A typical operation sequences during the cyclic test, the $\mathrm{H}_{2}$ purity was determined at the time with the red dots; the influence of $\mathbf{b}$ current densities, $\mathbf{c}$ temperature, and $\mathbf{d}$ flow rate on the potential bias, other than specified, current density is $750 \mathrm{~mA}$ $\mathrm{cm}^{-2}$, temperature is $35^{\circ} \mathrm{C}$ and flow rate is $50 \mathrm{ml} \mathrm{min}^{-1}$, anolyte/catholyte swap is not applied for simplicity. Both anolyte and catholyte are $1.0 \mathrm{M} \mathrm{KOH}$ solutions.

while outperforming the classic alkaline water and conventional decoupled electrolyzer, using redox couples (CE, see Supplementary Figs. 18-19). We also investigated the influence of the compartment temperature on water splitting, satisfactory applied voltages were recorded above $35^{\circ} \mathrm{C}$ (Fig. 4c). This low operating temperature promised to significantly save the heating energy. The flow rate of anolyte/catholyte was another vital factor controlling the reaction kinetics (see Fig. 4d). Thanks to the facilitated mass transport at $50 \mathrm{ml} \mathrm{min}^{-1}$, the polarization loss was greatly reduced and stabilized.

We also used Archimedes' method to quantify the generated gas volume over time at $200 \mathrm{~mA}$ (see Fig. 5a). After $45 \mathrm{~min}, 2.77 \mathrm{mmol}$ of $\mathrm{H}_{2}$ has been measured, which was close to the theoretical value ( $2.8 \mathrm{mmol}$ ), the calculated Faradaic efficiency was $96.5 \%$. The loss was ascribed to the charge/discharge of the auxiliary electrode and the polarization of the electrode. Figure $5 \mathrm{~b}$ compares the electrochemical impedance spectra (EIS) of electrolyzers with various architectures at open circuit voltage $(\mathrm{OCV})$. The area specific resistance of MFE was as low as $0.17 \Omega \mathrm{cm}^{2}$, comparable with that of PEMEC yet much lower than that of singlecompartment cell, $\mathrm{H}$-cell and the control cell $\left(\mathrm{NiOOH} / \mathrm{Ni}(\mathrm{OH})_{2}\right.$ redox couple was used yet no flow or sandwiched electrode structure, see details in Supplementary Figs. 18 and 22).

Importantly, the overall water splitting in the MFE was performed equally well in both deionized water and regular tap water containing various metal cations (see Fig. $5 \mathrm{c}$, $\mathrm{d}$ and Supplementary Fig. 24). After $24 \mathrm{~h}$ test at $750 \mathrm{~mA} \mathrm{~cm}^{-2}$ in deionized water electrolyte, little degradation has been observed. The hardness of the used tap water was $179 \mathrm{mg} \mathrm{L}^{-1}$ (equivalent concentration as calcium carbonate, mainly originated from $\mathrm{Ca}^{2+}$ and $\mathrm{Mg}^{2+}$ ). Other soluble and solid contaminants can be found in Supplementary Table 4 . Albeit that these cations are known to be detrimental to PEMEC water electrolysis, it seems that MFE is not affected. The potential bias at $750 \mathrm{~mA} \mathrm{~cm}^{-2}$ was increased slightly by $60-70 \mathrm{mV}$ compared with that in the deionized water, yet was also essentially stable during $24 \mathrm{~h}$ test. In Supplementary Fig. 25, we also showed a $500 \mathrm{~h}$ stable operation of MFE in tap water electrolyte. The overpotential at $750 \mathrm{~mA} \mathrm{~cm}^{-2}$ increased by $8.95 \%$ after $500 \mathrm{~h}$ longevity test, suggesting that both the working and auxiliary electrodes were robust under the operating conditions.

\section{Discussion}

Our membrane-free flow electrolyzer can generate $\mathrm{H}_{2}$ with high purity $(>99.1 \%)$. The sandwich-like architecture enabled low ohmic loss, whereas the cost-effective $\mathrm{FeP}-\mathrm{CoP} / \mathrm{NC}$ bifunctional catalysts guaranteed the efficient and stable overall water splitting in MFE in cyclic mode. The highest current density reached 750 $\mathrm{mA} \mathrm{cm}{ }^{-2}$ under the potential bias of $2.1 \mathrm{~V}$ and ambient conditions, in both deionized and tap water electrolyte. Scaling up of this cell technology requires a complete techno-economic analysis, particularly taking into account the auxiliary electrode cost. In addition, the redox stability of the working and auxiliary electrodes in the tap water electrolyte should be further evaluated. Nevertheless, this work demonstrates the opportunity of combining the advantages of conventional alkaline electrolyzer with low materials/operation costs and PEMEC with high current densities, opening a path for sustainable hydrogen generation.

\section{Methods}

Materials and reagents. All chemical reagents and materials, including Co $\left(\mathrm{NO}_{3}\right)_{2} \cdot 6 \mathrm{H}_{2} \mathrm{O}, \mathrm{Fe}\left(\mathrm{NO}_{3}\right)_{3} \cdot 9 \mathrm{H}_{2} \mathrm{O}, \mathrm{NaH}_{2} \mathrm{PO}_{2} \cdot \mathrm{H}_{2} \mathrm{O},\left(\mathrm{MgCO}_{3}\right)_{4} \mathrm{Mg}(\mathrm{OH})_{2}, \mathrm{~N}$ $\left(\mathrm{CH}_{2} \mathrm{COOH}\right)_{3}$ were used without purification. Nafion solution was obtained from E.I. Du Pont. $\mathrm{Ni}(\mathrm{OH})_{2}, \mathrm{CoO}$, polytetrafluoroethylene (PTFE), porous separator and carboxymethylcellulose (CMC) were provided by NewCom energy material store. Deionized water (DI) was used for the materials synthesis.

Preparation of FeP-CoP/NC and the control samples (FeP/NC, CoP/NC, FePCoP, and FeP-CoP/C). Preparation of porous N doped carbon (NC). The NC was synthesized according to our previous work ${ }^{57}$. 

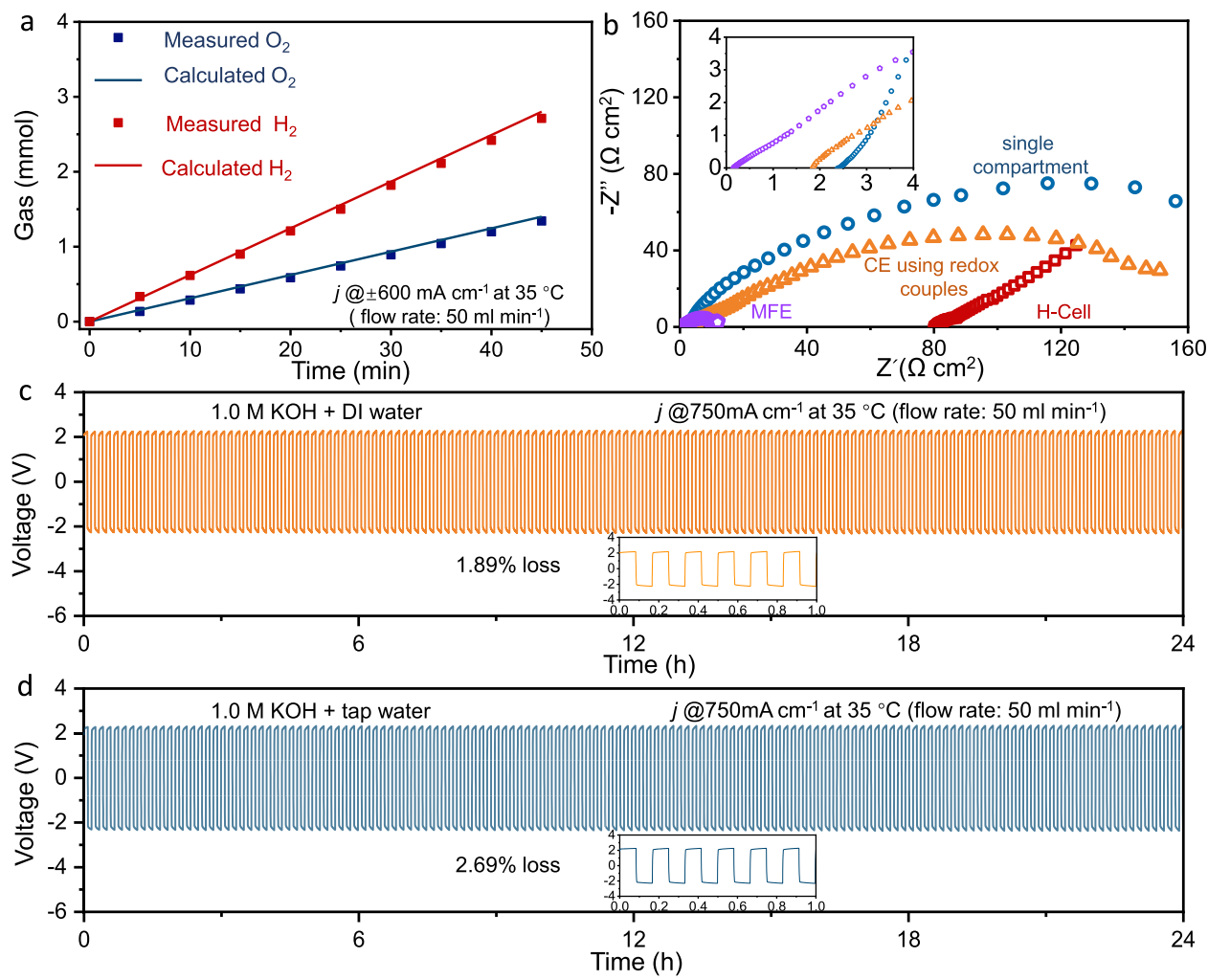

Fig. 5 Stability test of MFE in overall water splitting. a Measured $\mathrm{H}_{2}$ and $\mathrm{O}_{2}$ yields using Archimedes' method, solids lines represent the gas evolution at $100 \%$ Faradaic efficiency; b EIS spectra of cells with different architectures, all electrodes are employed with FeP-CoP/NC catalysts; cyclic stability test of MFE in $\mathbf{c}$ deionized water and $\mathbf{d}$ tap water electrolyte, the precipitation in the tap water electrolyte, after adding $\mathrm{KOH}$, has been removed; anolyte/catholyte swap is not applied for simplicity.

Preparation of FeP-CoP/NC. We used the classic infiltration method. $60 \mathrm{mg}$ NC was added to the solution containing $2 \mathrm{mmol} \mathrm{Fe}\left(\mathrm{NO}_{3}\right)_{3} \cdot 9 \mathrm{H}_{2} \mathrm{O}$ and $2 \mathrm{mmol} \mathrm{Co}\left(\mathrm{NO}_{3}\right)_{2}$ $.6 \mathrm{H}_{2} \mathrm{O}$ dissolved in $15 \mathrm{~mL}$ DI water. The resulting suspension was stirred at $65^{\circ} \mathrm{C}$ for $12 \mathrm{~h}$ until water evaporated completely. The obtained powder was reduced in a tubular furnace at $550^{\circ} \mathrm{C}$ for $2 \mathrm{~h}$ in $5 \% \mathrm{H}_{2}$ atmosphere to form $\mathrm{Fe}$-Co bimetallic alloy/NC. Then, $\mathrm{Fe}-\mathrm{Co}$ bimetallic alloy/NC and $\mathrm{NaH}_{2} \mathrm{PO}_{2} \cdot \mathrm{H}_{2} \mathrm{O}$ were placed at two separate positions in a tube with the stream of $\mathrm{Ar} \mathrm{NaH}_{2} \mathrm{PO}_{2} \cdot \mathrm{H}_{2} \mathrm{O}$ was placed at the upstream side. The mass ratio of $\mathrm{NaH}_{2} \mathrm{PO}_{2} \cdot \mathrm{H}_{2} \mathrm{O}$ and $\mathrm{Fe}-\mathrm{Co}$ bimetallic alloy/NC was 5:1. The sample was heated up to $300^{\circ} \mathrm{C}$ for 120 min to form FeP-CoP/NC. FeP/NC, $\mathrm{CoP} / \mathrm{NC}, \mathrm{FeP}-\mathrm{CoP}$, and $\mathrm{FeP}-\mathrm{CoP} / \mathrm{C}$ were prepared using the same approach.

Preparation of the modified electrode. The glassy carbon electrode (GC) $(\Phi=3$ $\mathrm{mm}, A: 0.0706 \mathrm{~cm}^{2}$ ) was polished with 0.3 and $0.05 \mu \mathrm{m}$ alumina powders, and rinsed with acetone, ethanol, and DI water. GC was calibrated in $1.0 \mathrm{mM} \mathrm{K}_{3} \mathrm{Fe}$ $(\mathrm{CN})_{6}+1.0 \mathrm{mM} \mathrm{K}_{4} \mathrm{Fe}(\mathrm{CN})_{6}+0.1 \mathrm{M} \mathrm{KCl}$ (see CV in Supplementary Fig. 1). The catalyst ink contained $3 \mathrm{mg}$ catalyst, $50 \mu \mathrm{L} 5 \mathrm{wt} \%$ Nafion solution, $50 \mu \mathrm{L}$ DI water and $900 \mu \mathrm{L}$ ethanol. After sonication for $2 \mathrm{~h}, 8 \mu \mathrm{L}$ of catalyst ink was drop-casted on the polished GC (mass loading $0.340 \mathrm{mg} \mathrm{cm}^{-2}$ ) and dried in air.

\section{Preparation of FeP-CoP/NC coated carbon cloth electrodes (FeP-CoP/NC/} CC). $\mathrm{FeP}-\mathrm{CoP} / \mathrm{NC}$ was brush-painted on the cleaned carbon cloth $(2 \times 2 \mathrm{~cm})$, the mass loading of $\mathrm{FeP}-\mathrm{CoP} / \mathrm{NC}$ was $3.17 \mathrm{mg} \mathrm{cm}^{-2}$. The obtained $\mathrm{FeP}-\mathrm{CoP} / \mathrm{NC} / \mathrm{CC}$ was dried in a vacuum oven overnight to remove all the organic solvents.

Preparation of $\mathrm{Ni}(\mathrm{OH})_{2}$ auxiliary electrode (AE). $1.32 \mathrm{~g} \mathrm{Ni}(\mathrm{OH})_{2}, 0.2493 \mathrm{~g} \mathrm{CoO}$, $0.0665 \mathrm{~g}$ polytetrafluoroethylene (PTFE), and $0.016625 \mathrm{~g}$ carboxymethylcellulose $(\mathrm{CMC})$ were mixed with water to form the slurry. The slurry was sequentially brush painted on a piece of cleaned $\mathrm{Ni}$ foam $(2 \times 2 \mathrm{~cm})$, dried and pressed under a pressure of $20 \mathrm{MPa}$. The mass loading of $\mathrm{Ni}(\mathrm{OH})_{2}$ was $330 \mathrm{~m} \mathrm{~cm}^{-2}$. To prevent the delamination of the coated film under redox cycle in reaction, this coated Ni piece was then sandwiched by two pristine Ni foam piece, as shown in Supplementary Fig. 2, and pressed again under a pressure of $20 \mathrm{MPa}$ to form the final AE.

Assembly of MFE. Both compartments of MFE were comprised of the endplates, current collectors, a bifunctionally active electrode $(1 \times 0.333 \mathrm{~cm})$, a porous separator $(130 \mu \mathrm{m}$-thick) and an AE $(1 \times 2 \mathrm{~cm})$, respectively. Two AEs were connected by a copper strip. Two peristaltic pumps were used to enable the flow of electrolyte.
Materials characterizations. X-ray diffraction (XRD) patterns were obtained by using a D8 Advance X-ray diffractometer with Cu Ka radiation $(\lambda=1.5418 \AA \AA)$. Diffraction patterns were collected by step scanning in the $2 \theta$ range of $20-80^{\circ}$ with an interval of $0.02^{\circ}$. The morphologies were investigated by a field-emission scanning electron microscopy (FE-SEM, Hitachi S-4800). Transmission electron microscopy (TEM) and elemental mapping were collected by using a TEM (JEOL, JEM-2100F) equipped with an energy-disperse X-ray spectrometer (EDX) attachment. The surface analysis was performed by X-ray photoelectron spectroscopy (XPS, ESCALab 250Xi Thermo Scientific) with $\mathrm{Al} \mathrm{Ka}(\mathrm{h} v=1486.6 \mathrm{eV})$ radiation All the binding energies were calibrated to the adventitious $\mathrm{C} 1 s$ peak at $284.8 \mathrm{eV}$ Brunauer-Emmett-Teller (BET) were obtained by a Belsorp-Mini II (BEL Japan Inc., Japan) at $77 \mathrm{~K}$ in $\mathrm{N}_{2}$. Gas purity was measured using an online gas chromatography (Fuli GC9730).

Electrochemical characterizations. All electrochemical measurements were performed using a potentiostat (Autolab pgstat M204). In a typical three-electrode system, $1 \mathrm{M} \mathrm{KOH}$ solution was used as the electrolyte, a platinum plate $(0.5 \times 0.5$ $\mathrm{cm}$ ) was used as the counter electrode, a saturated calomel electrode (SCE) was used as the reference electrode. In the OER and HER measurement, the electrolyte was saturated by $\mathrm{O}_{2}$ and $\mathrm{H}_{2}$ in advance, respectively. Linear sweep voltammetry (LSV) and cyclic voltammetry (CV) were performed at $5 \mathrm{mV} \mathrm{s}^{-1}$. The Tafel slope was calculated using the Tafel equation:

$$
\eta=b \log (j)+a
$$

$(\eta, b$, and $j$ represent the overpotential, Tafel slope, and current density, respectively), and a scan rate of $5 \mathrm{mV} \mathrm{s}^{-1}$ was used to obtain the polarization curves for Tafel plots. Electrochemical impedance spectra (EIS) were recorded at frequencies ranging from $10^{5} \mathrm{~Hz}$ to $0.1 \mathrm{~Hz}$. The long-term stability tests of OER and HER were performed by chronoamperometry and chronopotentiometry. All the potentials reported in our work were relative to the reversible hydrogen electrode (RHE) using the conversion equation below:

$$
\mathrm{E}_{\mathrm{RHE}}=\mathrm{E}_{\mathrm{SCE}}+0.059 \times \mathrm{pH}+0.242 \mathrm{~V} \text {. }
$$

Faradaic efficiency measurement. We used Archimedes' method to measure the volume of the collected gas at several time points during electrolysis. Faradaic 
efficiency (FE) was calculated according to the following equation:

$$
F E=\frac{n(\text { gas })_{\text {measured }}}{n(\text { gas })_{\text {calculated }}}=\frac{P V(\text { gas })_{\text {measured }} / \mathrm{R} T}{Q / z \mathrm{~F}}
$$

wherein $P$ is the pressure ( $1 \mathrm{~atm}), V$ is the volume of the generated gas, $\mathrm{R}$ is gas constant $\left(8.314 \mathrm{~J} \mathrm{~mol}^{-1} \mathrm{~K}^{-1}\right), T$ is temperature $(298 \mathrm{~K}), Q=\int I \mathrm{dt}$ is the charge, $z$ is the stoichiometric charge number (2 electrons per $\mathrm{H}_{2}$ molecule and 4 electrons per $\mathrm{O}_{2}$ molecule), and $\mathrm{F}$ is Faraday constant $\left(\mathrm{F}=96485.34 \mathrm{C} \mathrm{mol}^{-1}\right)$.

Activation of AEs. The $\mathrm{NiOOH} / \mathrm{Ni}(\mathrm{OH})_{2}$ redox couple was generated in situ. In the original MFE assembly as shown in Supplementary Fig. 5, both AEs contained $\mathrm{Ni}(\mathrm{OH})_{2}$ only. The activation process was carried out by periodically applying $\pm 250 \mathrm{~mA}$ current to MFE (30 min per cycle for 40 cycles) to generate $\mathrm{NiOOH}$ on AE:

$$
\mathrm{Ni}(\mathrm{OH})_{2}+\mathrm{OH}^{-} \rightarrow \mathrm{NiOOH}+\mathrm{H}_{2} \mathrm{O}+e^{-}
$$

\section{Data availability}

The data that supports the plots of this paper and other findings of this study are available from the corresponding authors upon reasonable request.

Received: 4 March 2021; Accepted: 9 June 2021;

Published online: 06 July 2021

\section{References}

1. Huang, S. et al. N-, O-, and S-tridoped carbon-encapsulated $\mathrm{Co}_{9} \mathrm{~S}_{8}$ nanomaterials: efficient bifunctional electrocatalysts for overall water splitting. Adv. Funct. Mater. 27, 1606585 (2017).

2. Niether, C. et al. Improved water electrolysis using magnetic heating of FeC-Ni core-shell nanoparticles. Nat. Energy 3, 476-483 (2018).

3. Zhang, Q., Bedford, N. M., Pan, J., Lu, X. \& Amal, R. A fully reversible water electrolyzer cell made up from FeCoNi (Oxy)hydroxide atomic Layers. Adv. Energy Mater. 9, 1901312 (2019).

4. Guo, M. et al. In situ conversion of metal ( $\mathrm{Ni}, \mathrm{Co}$ or $\mathrm{Fe})$ foams into metal sulfide $\left(\mathrm{Ni}_{3} \mathrm{~S}_{2}, \mathrm{Co}_{9} \mathrm{~S}_{8}\right.$ or $\left.\mathrm{FeS}\right)$ foams with surface grown $\mathrm{N}$-doped carbon nanotube arrays as efficient superaerophobic electrocatalysts for overall water splitting. J. Mater. Chem. A 8, 9239-9247 (2020).

5. Sun, $\mathrm{H}$. et al. Boosting activity on $\mathrm{Co}_{4} \mathrm{~N}$ porous nanosheet by coupling $\mathrm{CeO}_{2}$ for efficient electrochemical overall water splitting at high current densities. Adv. Funct. Mater. 30, 1910596 (2020).

6. Suryanto, B. H. R., Wang, Y., Hocking, R. K., Adamson, W. \& Zhao, C. Overall electrochemical splitting of water at the heterogeneous interface of nickel and iron oxide. Nat. Commun. 10, 5599-5609 (2019).

7. Hui, L. et al. Overall water splitting by graphdiyne-exfoliated and -sandwiched layered double-hydroxide nanosheet arrays. Nat. Commun. 9, 5309-5319 (2018).

8. van Troostwijk, A. \& Deiman, J. R. Sur une manière de décomposer l'Eau en Air inflammable et en Air vital. Obs Phys. 35, 369-378 (1789).

9. Trasatti, S. Water electrolysis: who first? J. Electroanal. Chem. 476, 90-91 (1999).

10. Ursua, A., Gandia, L. M. \& Sanchis, P. Hydrogen production from water electrolysis: current status and future trends. Proc. IEEE 100, 410-426 (2012).

11. You, B. \& Sun, Y. Chalcogenide and phosphide solid-state electrocatalysts for hydrogen generation. Chempluschem 81, 1045-1055 (2016).

12. Lin, Y., Gao, Y. \& Fan, Z. Printable fabrication of nanocoral-structured electrodes for high-performance flexible and planar supercapacitor with artistic design. Adv. Mater. 29, 1701736 (2017).

13. Li, D., Park, E. J., Zhu, W., Shi, Q. \& Kim, Y. S. Highly quaternized polystyrene ionomers for high performance anion exchange membrane water electrolysers. Nat. Energy 5, 1-8 (2020).

14. Liu, C. et al. Performance enhancement of PEM electrolyzers through iridiumcoated titanium porous transport layers. Electrochem. Commun. 97, 96-99 (2018).

15. Vengatesan, S., Santhi, S., Jeevanantham, S. \& Sozhan, G. Quaternized poly (styrene-co-vinylbenzyl chloride) anion exchange membranes for alkaline water electrolysers. J. Power Sources 284, 361-368 (2015).

16. Smith, D. W. et al. A microblock ionomer in proton exchange membrane electrolysis for the production of high purity hydrogen. Macromolecules $\mathbf{4 6}$, 1504-1511 (2013).

17. Chen, L., Dong, X., Wang, Y. \& Xia, Y. Separating hydrogen and oxygen evolution in alkaline water electrolysis using nickel hydroxide. Nat. Commun. 7, 11741-11749 (2016).

18. Araya, S. S. \& Kær, S. K. Long-term contamination effect of iron ions on cell performance degradation of proton exchange membrane water electrolyser. J. Power Sources 434, 226755-226762 (2019).
19. Tang, H., Peikang, S., Jiang, S. P., Wang, F. \& Pan, M. A degradation study of nafion proton exchange membrane of PEM fuel cells. J. Power Sources 170, 85-92 (2007)

20. Leng, Y. et al. Solid-state water electrolysis with an alkaline membrane. J. Am. Chem. Soc. 134, 9054-9057 (2012).

21. Zhou, H. et al. Water splitting by electrolysis at high current densities under 1.6 volts. Energy Environ. Sci. 11, 2858-2864 (2018)

22. Firouzjaie, H. A. \& Mustain, W. E. Catalytic advantages, challenges and priorities in alkaline membrane fuel cells. ACS Catal. 10, 225-234 (2019).

23. Landman, A. et al. Photoelectrochemical water splitting in separate oxygen and hydrogen cells. Nat. Mater. 16, 646-651 (2017).

24. Gillespie, M. I. \& Kriek, R. J. Scalable hydrogen production from a monocircular filter press divergent electrode-flow-through alkaline electrolysis stack. J. Power Sources 397, 204-213 (2018).

25. Talabi, O. O., Dorfi, A. E., O'Neil, G. D. \& Esposito, D. V. Membraneless electrolyzers for the simultaneous production of acid and base. Chem. Commun. 53, 8006-8009 (2017).

26. Yang, F., Kim, M. J., Brown, M. \& Wiley, B. J. Alkaline water electrolysis at 25 A $\mathrm{cm}^{-2}$ with a microfibrous flow-through electrode. Adv. Energy Mater. 10, 2001174 (2020).

27. Clarke, R. E., Giddey, S. \& Badwal, S. Stand-alone PEM water electrolysis system for fail safe operation with a renewable energy source. Int. J. Hydrog. Energy 35, 928-935 (2010).

28. Amstutz, V. et al. Renewable hydrogen generation from a dual-circuit redox flow battery. Energy Environ. Sci. 7, 2350-2358 (2014).

29. Goodwin, S. \& Walsh, D. A. Closed bipolar electrodes for spatial separation of $\mathrm{H}_{2}$ and $\mathrm{O}_{2}$ evolution during water electrolysis and the development of highvoltage fuel cells. ACS Appl. Mat. Interfaces 9, 23654-23661 (2017).

30. Dotan, H. et al. Decoupled hydrogen and oxygen evolution by a two-step electrochemical-chemical cycle for efficient overall water splitting. Nat. Energy 4, 786-795 (2019).

31. Li, Y. et al. Implanting Ni-O-VOx sites into Cu-doped $\mathrm{Ni}$ for low-overpotential alkaline hydrogen evolution. Nat. Commun. 11, 2720-2728 (2020).

32. Lagadec, M. F. \& Grimaud, A. Water electrolysers with closed and open electrochemical systems. Nat. Mater. 19, 1140-1150 (2020).

33. Ben-Jacob, E. \& Garik, P. The formation of patterns in non-equilibrium growth. Nature 343, 523 (1990).

34. Huang, J. et al. Decoupled amphoteric water electrolysis and its integration with $\mathrm{Mn}-\mathrm{Zn}$ battery for flexible utilization of renewables. Energy Environ. Sci. 14, 883-889 (2021).

35. Gillespie, M. I. \& Kriek, R. J. Hydrogen production from a rectangular horizontal filter press divergent electrode-flow-through (DEFT $\left.{ }^{\mathrm{m}}\right)$ alkaline electrolysis stack. J. Power Sources 372, 252-259 (2017).

36. You, B. \& Sun, Y. Innovative strategies for electrocatalytic water splitting. Acc. Chem. Res. 51, 1571-1580 (2018).

37. Xiang, C., Papadantonakis, K. M. \& Lewis, N. S. Principles and implementations of electrolysis systems for water splitting. Mater. Horiz. 3, 169-173 (2016).

38. Gillespie, M. I., van der Merwe, F. \& Kriek, R. J. Performance evaluation of a membraneless divergent electrode-flow-through (DEFT) alkaline electrolyser based on optimisation of electrolytic flow and electrode gap. J. Power Sources 293, 228-235 (2015).

39. $\mathrm{Li}, \mathrm{Z}$. et al. Core-shell structured $\mathrm{CoP} / \mathrm{FeP}$ porous microcubes interconnected by reduced graphene oxide as high performance anodes for sodium ion batteries. Nano Energy 32, 494-502 (2017).

40. Zhou, B., Yan, F., Li, X., Zhou, J. \& Zhang, W. An interpenetrating porous organic polymer as a precursor for $\mathrm{FeP} / \mathrm{Fe}_{2} \mathrm{P}$-embedded porous carbon toward a pH-universal ORR catalyst. Chemsuschem 12, 915-923 (2019).

41. Liu, T. et al. CoP-doped MOF-based electrocatalyst for $\mathrm{pH}$-universal hydrogen evolution reaction. Angew. Chem. Int Ed. 14, 4679-4684 (2019).

42. Tang, C. et al. Fe-doped CoP nanoarray: a monolithic multifunctional catalyst for highly efficient hydrogen generation. Adv. Mater. 29, 1602441 (2017).

43. Li, H., Xu, S. M., Yan, H., Yang, L. \& Xu, S. Cobalt phosphide composite encapsulated within $\mathrm{N}$, P-doped carbon nanotubes for synergistic oxygen evolution. Small 14, 1800367 (2018).

44. Lv, Y. et al. Fe-Co alloyed nanoparticles catalysed efficient hydrogenation of cinnamaldehyde to cinnamyl alcohol in water. Angew. Chem. Int. Ed. 59, 23521-23526 (2020)

45. Liu, T., Wang, K., Du, G., Asiri, A. M. \& Sun, X. Self-supported CoP nanosheet arrays: a non-precious metal catalyst for efficient hydrogen generation from alkaline NaBH4 solution. J. Mater. Chem. A 4, 13053-13057 (2016).

46. Yao, C. et al. Atomically-precise dopant-controlled single cluster catalysis for electrochemical nitrogen reduction. Nat. Commun. 11, 4389-4399 (2020).

47. Wang, J. et al. Heteroatom-doping of non-noble metal-based catalysts for electrocatalytic hydrogen evolution: an electronic structure tuning strategy. Small Methods 5, 2000988 (2021)

48. Hua, B. et al. Stabilizing double perovskite for effective bifunctional oxygen electrocatalysis in alkaline conditions. Chem. Mater. 29, 6228-6237 (2017). 
49. $\mathrm{Xu}, \mathrm{J}$. et al. Boosting the hydrogen evolution performance of ruthenium clusters through synergistic coupling with cobalt phosphide. Energy Environ. Sci. 11, 1819-1827 (2018).

50. Zhang, Q. et al. Iron-doped NiCoP porous nanosheet arrays as a highly efficient electrocatalyst for oxygen evolution reaction. ACS Appl. Energy Mater. 1, 571-579 (2018).

51. Jiao, L., Zhou, Y. X. \& Jiang, H. Metal-organic framework-based CoP/reduced graphene oxide: high-performance bifunctional electrocatalyst for overall water splitting. Chem. Sci. 7, 1690-1695 (2016).

52. Yan, X. et al. "Nano-garden cultivation" for electrocatalysis: controlled synthesis of nature-inspired hierarchical nanostructures. J. Mater. Chem. A 8, 7626 (2020).

53. Boppella, R., Tan, J., Yang, W. \& Moon, J. Homologous CoP/NiCoP heterostructure on $\mathrm{N}$-doped carbon for highly efficient and $\mathrm{pH}$-universal hydrogen evolution electrocatalysis. Adv. Funct. Mater. 29, 1807976 (2019).

54. Guan, C. et al. Hollow Mo-doped CoP nanoarrays for efficient overall water splitting. Nano Energy 48, 73-80 (2018).

55. Pan, Y. et al. Core-shell ZIF-8@ZIF-67 derived CoP nanoparticles-embedded $\mathrm{N}$-doped carbon nanotube hollow polyhedron for efficient over-all water splitting. J. Am. Chem. Soc. 140, 2610-2618 (2018)

56. Liu, T. et al. Nickel-Cobalt phosphide nanowires supported on Ni foam as a highly efficient catalyst for electrochemical hydrogen evolution reaction. Int. J. Hydrog. Energy 42, 14124-14132 (2017).

57. Eisenberg, D. et al. A simple synthesis of an N-doped carbon ORR catalyst: hierarchical micro/meso/macro porosity and graphitic shells. Chem. Eur. J. 22, 501-505 (2016).

\section{Acknowledgements}

We acknowledge the funding through the Jiangsu Provincial Department of Science and Technology (BK20190216) and Wuhan University. J.B., G.R., and N.Y. acknowledge the financial support from the Netherlands Organization for Scientific Research (NWO) NWO-GDST Advanced Materials program (729.001.022).

\section{Author contributions}

Ning Yan conceived and designed the research, wrote/revised this manuscript. Xiaoyu Yan performed the bifunctional catalyst synthesis, MFE design, electrochemical experi- ments, and wrote the manuscript. Jasper Biemolt prepared the carbon materials and helped to analyze the data with Kai Zhao, Yang Zhao, Xiaojuan Cao, and Xiaoyu Wu Ying Yang gave important help in theoretical calculations. Gadi Rothenberg gave helpful advice on the manuscript preparation.

\section{Competing interests}

The authors declare no competing interests.

\section{Additional information}

Supplementary information The online version contains supplementary material available at https://doi.org/10.1038/s41467-021-24284-5.

Correspondence and requests for materials should be addressed to N.Y.

Peer review information Nature Communications thanks Roelof Kriek and other, anonymous, reviewers for their contribution to the peer review of this work.

Reprints and permission information is available at http://www.nature.com/reprints

Publisher's note Springer Nature remains neutral with regard to jurisdictional claims in published maps and institutional affiliations.

\begin{abstract}
(c) (i) Open Access This article is licensed under a Creative Commons Attribution 4.0 International License, which permits use, sharing, adaptation, distribution and reproduction in any medium or format, as long as you give appropriate credit to the original author(s) and the source, provide a link to the Creative Commons license, and indicate if changes were made. The images or other third party material in this article are included in the article's Creative Commons license, unless indicated otherwise in a credit line to the material. If material is not included in the article's Creative Commons license and your intended use is not permitted by statutory regulation or exceeds the permitted use, you will need to obtain permission directly from the copyright holder. To view a copy of this license, visit http://creativecommons.org/ licenses/by/4.0/
\end{abstract}

(C) The Author(s) 2021 